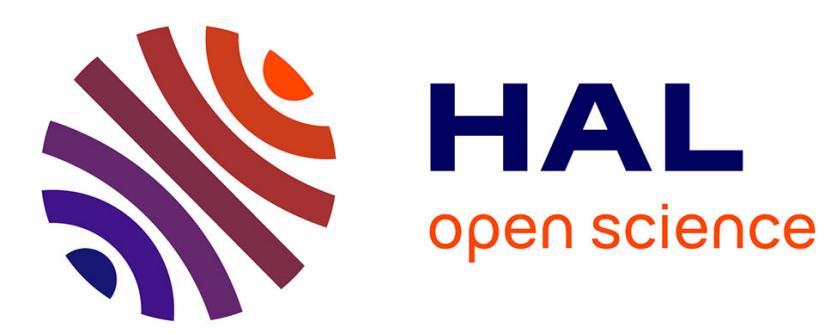

\title{
AN IMPROVED LITHIUM FLUORIDE MATERIAL FOR THERMOLUMINESCENCE DOSIMETRY
}

\author{
R. Nink, H.-J. Kos
}

\section{To cite this version:}

R. Nink, H.-J. Kos. AN IMPROVED LITHIUM FLUORIDE MATERIAL FOR THERMOLUMINESCENCE DOSIMETRY. Journal de Physique Colloques, 1976, 37 (C7), pp.C7-127-C7-131. 10.1051/jphyscol:1976725 . jpa-00216881

\section{HAL Id: jpa-00216881 https://hal.science/jpa-00216881}

Submitted on 1 Jan 1976

HAL is a multi-disciplinary open access archive for the deposit and dissemination of scientific research documents, whether they are published or not. The documents may come from teaching and research institutions in France or abroad, or from public or private research centers.
L'archive ouverte pluridisciplinaire HAL, est destinée au dépôt et à la diffusion de documents scientifiques de niveau recherche, publiés ou non, émanant des établissements d'enseignement et de recherche français ou étrangers, des laboratoires publics ou privés. 


\title{
AN IMPROVED LITHIUM FLUORIDE MATERIAL FOR THERMOLUMINESCENCE DOSIMETRY
}

\author{
R. NINK and H.-J. KOS
}

Physikalisch-Technische Bundesanstalt, Institut Berlin, BRD

\begin{abstract}
Résumé. - Un nouveau matériau TLD en LiF a été créé par une légère modification de la méthode d'incorporation du Ti. Ce matériau jouit de meilleures propriétés en ce qui concerne les traitements thermiques nécessaires pour les applications. Afin d'obtenir une réponse TL optimale, on utilise un refroidissement lent et non rapide.De plus, comme les pré-pics sont très bas, on peut éviter la cuisson longue à $80^{\circ} \mathrm{C}$.

Un nouveau pic TL $5^{\prime}$ situé entre les pics TL 4 et 5 du matériau habituel se révèle être le principal pic TLD significatif. Les comportements thermiques et optiques des défauts de structure générateurs du pic TL 5 ' diffèrent sensiblement de ceux qui engendraient le pic TL 5.
\end{abstract}

\begin{abstract}
By a slight modification of the Ti-incorporation manner a new LiF TLD material has been developed with improved properties concerning thermal treatments necessary in application. To obtain optimal TL response not quenching but slow cooling is used. Further, as the TL prepeaks are very low, the usual long time $80^{\circ} \mathrm{C}$ annealing cycle can be avoided.

A new TL peak 5 ' positioned between TL peak 4 and 5 of conventional material turns out to be the TLD relevant main peak. The thermal and optical behaviour of lattice defects responsible for TL peak $5^{\prime}$ markedly differ from those leading to TL peak 5 .
\end{abstract}

1. Introduction. $-\mathrm{LiF}: \mathrm{Mg}$, Ti is frequently applied in thermoluminescence dosimetry (TLD). Its glow curve normally consists of five thermoluminescence (TL) peaks conventionally labelled $1,2,3$ (TL prepeaks which are undesirable because they cause fading effects in the TLD measurements) and 4, 5 (main TL peaks used in TLD) as indicated in figure 1. To obtain reproducible glow curves a time consuming standard thermal pre-irradiation treatment is necessary which consists of annealing in the range $400^{\circ} \mathrm{C}-500{ }^{\circ} \mathrm{C}$ for $1 \mathrm{~h}$. To reduce the low-temperature peaks an additional treatment at $80^{\circ} \mathrm{C}$ for $24 \mathrm{~h}$ is necessary as was shown by Zimmerman et al. [1]. They also pointed out that a high cooling rate after high temperature annealing is necessary to obtain maximal TL response in the main TL peak region. This has been confirmed later by Carlsson [2], Dhar et al. [3] and recently in extensive studies of Bradbury et al. [4]. All these studies had been performed with the most widely applied commercial product «TLD 100 » (Harshaw Chemical Comp., Ohio).

Although very numereous investigations on TLDLiF have been carried out (for a survey see Becker [5]) the TL emission mechanism is not yet fully understood. There is no doubt only about $\mathrm{Mg}$ being necessary for the formation of the different electron traps and $\mathrm{Ti}$ for the formation of the activator.

Many attempts have been made to clearify the nature of the $\mathrm{Mg}$-associated electron traps. There is much reason to assume that TL peak 2 and 3 like peak 4 and
5 are somehow connected respectively, being created by electron traps of very similar structures $[4,6]$. For this and since peak 3 and 4 are not so well separable from the glow curve as peak 2 and 5 the heights of the latter are taken here as representatives. Peak 1 has not yet been discussed in detail because it fades rapidly at room temperature and therefore is not important.

Peak 2 has been correlated with pairs of $\mathrm{Mg}^{++}$ ions and $\mathrm{Li}^{+}$vacancies $\left(\mathrm{Mg}^{++} \mathrm{V}\right)$ by Grant and Cameron [7] using dielectric loss measurements and with certain qualifications by Dryden and Shuter [8]. Probably $\mathrm{Mg}^{++} \mathrm{V}$ is only one part of a more complicated peak 2 trap. Mayhugh et al. [9] supposed a configuration consisting of $\mathrm{Mg}^{++} \mathrm{V}$ and a $\mathrm{F}$ centre $\left(\mathrm{Z}_{\mathbf{1}}\right.$ centre). Jackson and Harris [10] found a quantitative correspondence between TL peak 2 height and the optical absorption strength at $380 \mathrm{~nm}$.

The same authors found a similar relationship between TL peak 5 and the $310 \mathrm{~nm}$ absorption band. Dielectric loss, ionic conductivity and TL measurements led to a model after which TL peak 5 depends on the presence of $\mathrm{Mg}^{++} \mathrm{V}$ clusters, i. e. dimers and trimers (for a survey see [6]). Mayhugh et al. [9] supposed a combination of dimer or trimer plus one or more $\mathrm{F}$ centres as a peak 5 trap for the interpretation of their results. This is an intermediate point of view between the assumption of a pure dimer or trimer as a peak 5 trap and the $Z_{2}$ centre $\left(\mathrm{Mg}^{++}-\mathrm{F}^{\prime}\right.$ centre pair) which we proposed recently in a simple model [11].

An optical absorption band due to Ti of TLD 
grade $\mathrm{LiF}$ at $200 \mathrm{~nm}$ also in the non-irradiated state was first found by Zimmerman and Jones [12]. Rossiter et al. [13, 14] found a close relationship between the Ti content and the height of this absorption band as well as the TL response of their crystals.

The TLD-LiF material described here shows some properties markedly unlike TLD 100 . These first results might be of interest for the general discussion about the TL mechanism of TLD-LiF.

2. Experimental details. - The crystals were grown from LiF powder (Merck, suprapur) after the Czochralski method [15]. The crystals indicated here as « $\mathrm{LiF} A$ » and « $\mathrm{LiF} \mathrm{B}$ » had been marked earlier using their doping numbers 80 and 92 respectively [15], both characterizing additions of $5000 \mathrm{ppm}$ (mass) $\mathrm{MgF}_{2}, 1250 \mathrm{ppm} \mathrm{SiO}_{2}$, and $25 \mathrm{ppm} \mathrm{TiO}_{2}$ in the initial powder mixture. By mass spectrographic analysis an amount of $300 \mathrm{ppm}$ (atomic) $\mathrm{Mg}$ and $3 \mathrm{ppm} \mathrm{Ti}$ was measured in both crystals, the content of $\mathrm{Si}$ is estimated to be about $80 \mathrm{ppm}$. These values are nearby those quoted for Harshaw material TLD 100 to be $300 \mathrm{ppm}$ (atomic) $\mathrm{Mg}, 40 \mathrm{ppm} \mathrm{Si}, 5 \mathrm{ppm} \mathrm{Ti}$ [5]. Indeed, our LiF $A$ appeared to be very similar to TLD 100 .

Although there is only one difference in the way of growing $\mathrm{LiF}$ A and $\mathrm{B}$ the properties are remarkably different. $\mathrm{LiF}$ A was prepared by directly adding $\mathrm{TiO}_{2}$ together with the other additions to the powder mixture. For the preparation of $\mathrm{LiF} B$ firstly a $\mathrm{LiF}$ crystal bulb was grown by adding $3 \%$ (mass) $\mathrm{TiO}_{2}$. The bulb was grinded and $800 \mathrm{ppm}$ (mass) of the resulting powder were used in the LiF B mixture, instead of $25 \mathrm{ppm} \mathrm{TiO}_{2}$ (mass) for $\mathrm{LiF} \mathrm{A}$. As has been shown recently [15] by a series of preparations changing the different dopant concentrations both LiF $\mathrm{A}$ and the «Ti-predoped $» \mathrm{LiF}$ B revealed optimal TL response.

The crystals, $8 \mathrm{~mm} \times 8 \mathrm{~mm} \times 2 \mathrm{~mm}$ in size, were always given a standard heat treatment in air of one hour at $480^{\circ} \mathrm{C}$ prior to cooling to room temperature at different rates. By cooling the furnace linearly using a temperature programmer cooling rates smaller than $1 \mathrm{~K} \mathrm{~min} .^{-1}$ were obtained. In the intermediate cooling rate region, between $10 \mathrm{~K} \mathrm{min.-1}$ and $60 \mathrm{~K}$ min. ${ }^{-1}$, the crystals were cooled naturally in different ways. For the fast cooling rate of roughly $6000 \mathrm{~K}$ min. ${ }^{-1}$ the crystals were dropped directly into liquid nitrogen. The cooling rates as indicated were measured at $170^{\circ} \mathrm{C}$ to make the results comparable to those of Bradbury et al. [4].

Irradiations were performed to exposures of $1 \mathrm{mC} \mathrm{kg}^{-1}(\approx 4 \mathrm{R}),{ }^{60} \mathrm{Sr}$, for the TL measurements or to exposures of $0.3 \mathrm{kC} \mathrm{kg}^{-1}(\approx 1.2 \mathrm{MR}), \mathrm{X}$-rays, $40 \mathrm{kV}$ tube voltage, for the absorption measurements. The glow curves were obtained from a commercial reader (SAPHYMO-SRAT LDT 20) with a heating rate of $2 \mathrm{~K} \mathrm{~s}^{-1}$. For the optical absorption measurements a ZEISS photometer PMQ 3 with quartz prism and nitrogen flow was used.
3. Results. - Figure 1 shows the glow curves of LiF A treated with three different cooling rates. An increase in the total thermoluminescence yield is evident as the cooling rate increases. This is in agreement with measurements of Bradbury et al. [4] for TLD 100. Figure 2 shows a similar plot for LiF $B$ demonstrating a remarkable difference in the TL behaviour of this crystal mainly in two respects. Firstly the low temperature TL pre-peaks nearly completely disappeared and only TL peak 5 retained. Secondly the height of TL peak 5 increases with decreasing cooling rate and the position of the maximum moves into the direction of lower temperature

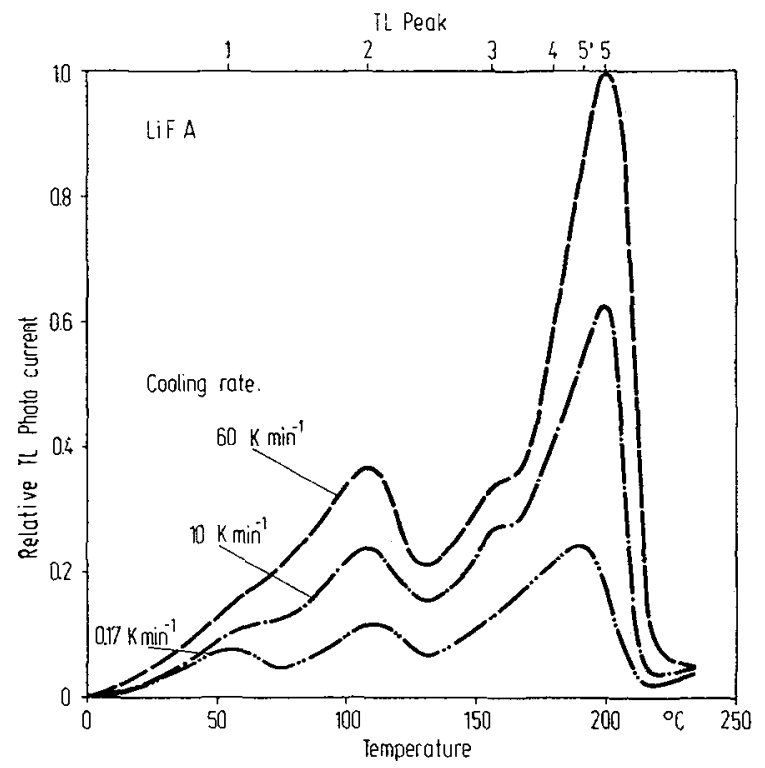

Fig. 1. - Glow curves of LiF A after cooling from $480^{\circ} \mathrm{C}$ with different cooling rates as indicated. Exposure : $90 \mathrm{Sr}$. $1 \mathrm{mC} \mathrm{kg}^{-1}(\approx 4 \mathrm{R})$.

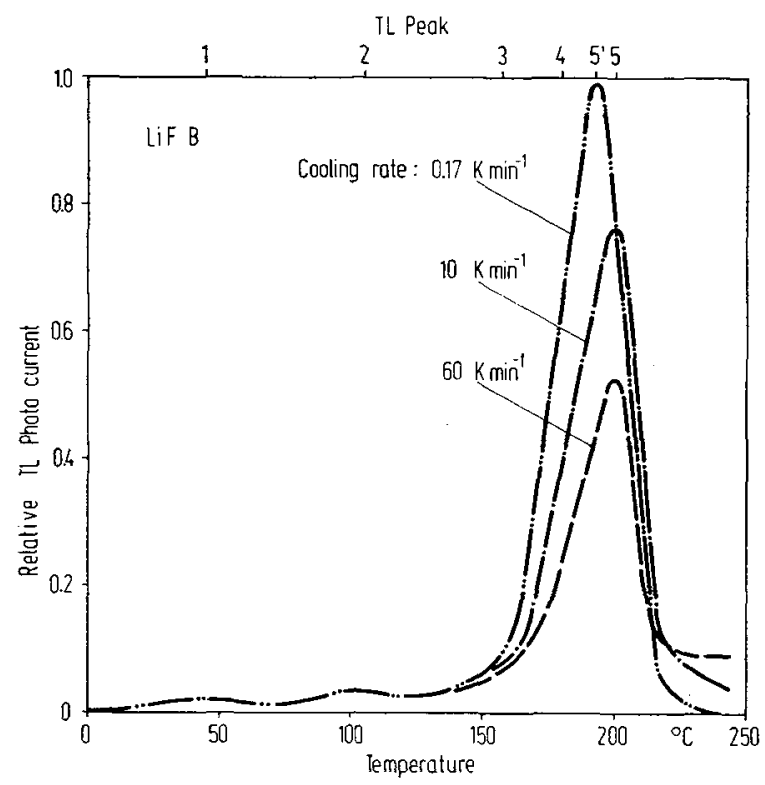

FIG. 2. - Glow curves of LiF B after cooling rates as indicated. Exposure : ${ }^{0} \mathrm{Sr}, 1 \mathrm{mC} \mathrm{kg}^{-1}(\approx 4 \mathrm{R})$. TL photo current scale as in figure 1 . 
This shift is only about $10^{\circ} \mathrm{C}$. As the difference of the positions of TL peak 4 and 5 is about $20^{\circ} \mathrm{C}$ in TLD $100[13,16,17]$ we conclude that a new TL peak is created in LiF B by low cooling rates which we call TL peak $5^{\prime}$ because it was not possible to separate it from peak 5. We take the height of the composed TL peak $5+5^{\prime}$ as a measure for the TL response of the main TL peak of our TLD material LiF B.

Figure 3 and figure 4 show the corresponding results

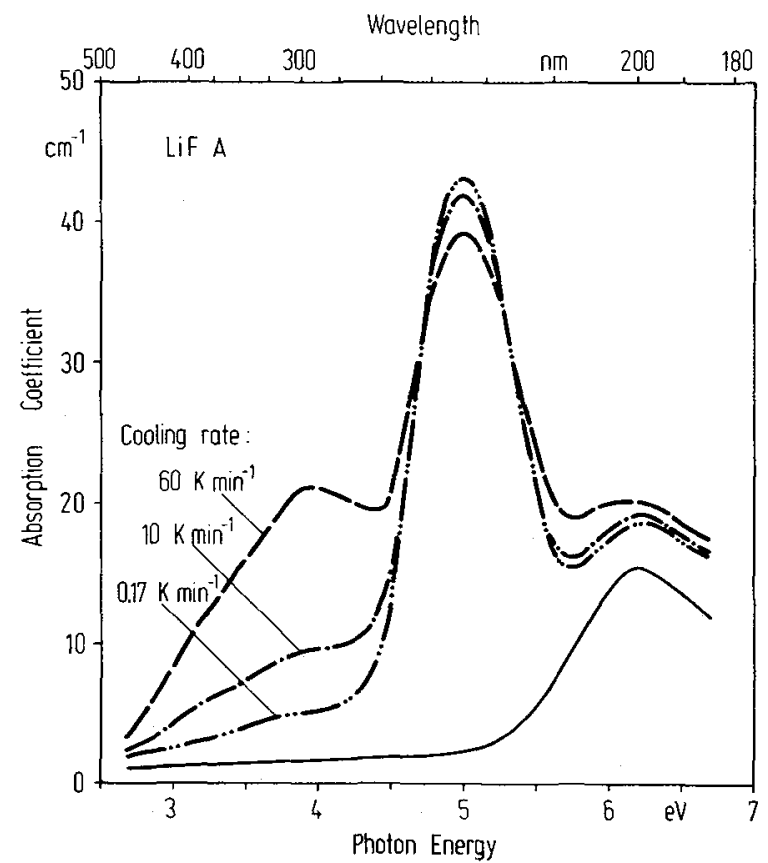

Fig. 3. - Optical absorption spectra of LiF A after cooling from $480^{\circ} \mathrm{C}$ with different cooling rates as indicated. Exposure : $\mathrm{X}$-ray, $0.3 \mathrm{kC} \mathrm{kg}^{-1}(\approx 1.2 \mathrm{MR})$. Solid line : unirradiated.

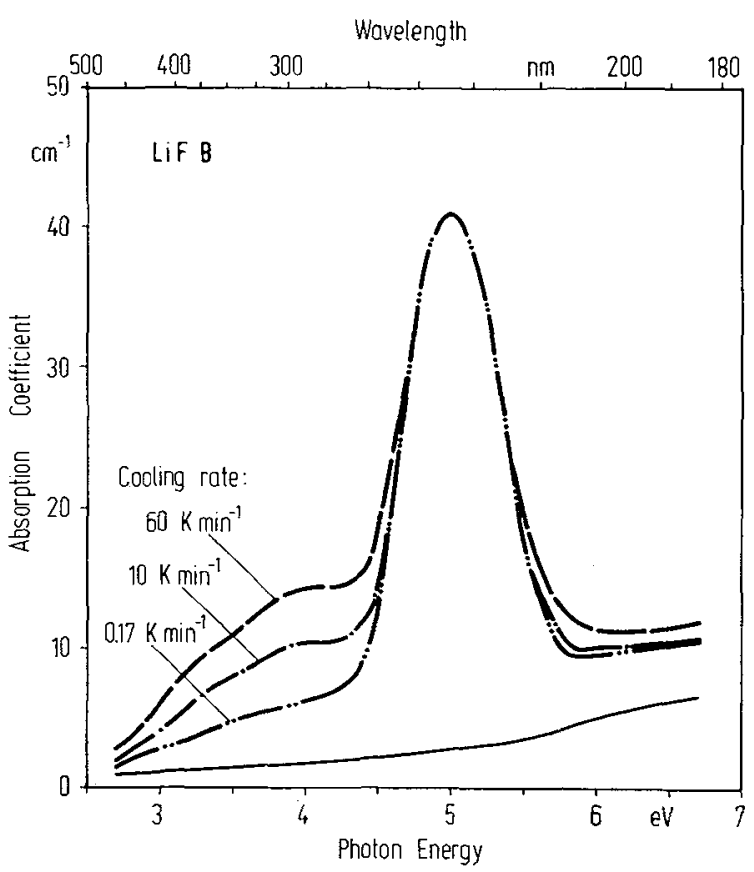

FIG. 4. - Optical absorption spectra of LiF B after cooling from $480^{\circ} \mathrm{C}$ with different cooling rates as indicated. Exposure : $\mathrm{X}$-ray, $0.3 \mathrm{kC} \mathrm{kg}^{-1}(\approx 1.2 \mathrm{MR})$. Solid line : unirradiated. of optical absorption measurements for the same cooling rates for both $\mathrm{LiF}$ types. The solid line in figure 3 for the unirradiated LiF A crystal exhibits the wellknown course of an absorption spectrum of a Ti-doped LiF crystal which is marked by an absorption band at $6.2 \mathrm{eV}[11,12,13]$. The irradiated crystal shows a strong dependence of the $380 \mathrm{~nm}$ and $310 \mathrm{~nm}$ absorption bands on the cooling rate, with increasing cooling rate their heights grow. A comparison with the curves of $\mathrm{LiF} B$ in figure 4 again shows an important difference : there is neither in the unirradiated nor in the irradiated state of LiF B any indication of a $\mathrm{Ti}$ absorption band in the absorption curves.

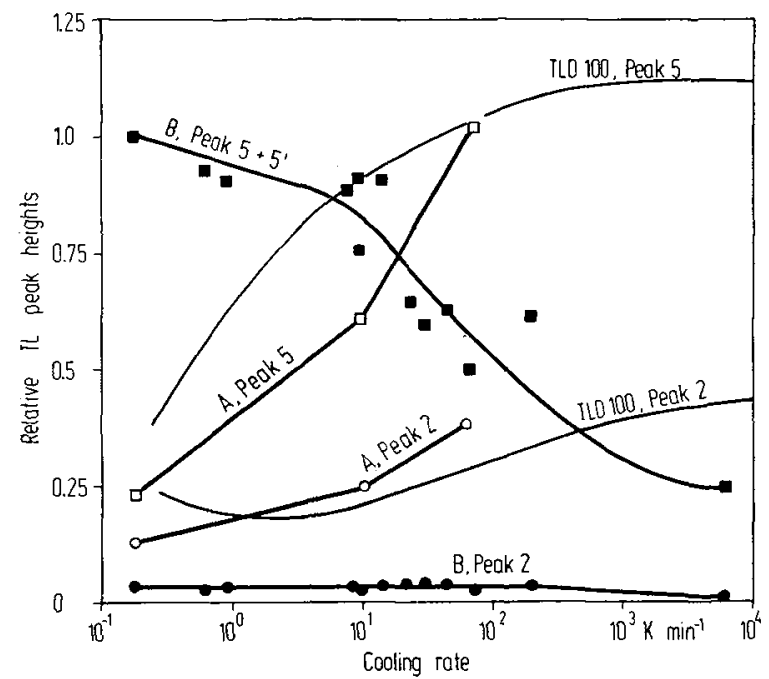

FIG. 5. - Relative TL peak heights versus cooling rate for TL peak 2 and 5 (resp. $5+5^{\prime}$ ) in $\operatorname{LiF} A$ and $\operatorname{LiF} B$. The results of Bradbury [4] at LiF TLD 100 are also inserted.

Figure 5 compares the peak heights of TL peak 2 and 5 in LiF A and TL peak 2 and $5+5^{\prime}$ in $\mathrm{LiF} B$ as a function of the cooling rate. The experimental data of Bradbury et al. [4] for TL peak 2 and 5 of TLD 100 are also inserted in the same peak height scale, taking into account that the heights of TL peak 5 of TLD 100 and TL peak $5+5^{\prime}$ of LiF B have been found earlier [15] to be equal after a cooling rate of $10 \mathrm{~K}$ $\min ^{-1}$. The important features of these curves are as follows :

(1) The dependence of TL peak 2 of TLD 100 and LiF A are very similar, both increase with cooling rate.

(2) On the contrary TL peak 2 of $\mathrm{LiF} B$ remains very low and nearly constant.

(3) TL peak 5 of TLD 100 and LiF A also behave similar. With decreasing cooling rates $(<100 \mathrm{~K}$ min. ${ }^{-1}$ ) this peak drops rather steeply. At high cooling rates peak 5 of TLD 100 seems to reach saturation. Such a saturation trend cannot be seen for LiF A because of lacking measuring points in this region.

(4) It is striking that TL peak $5+5^{\prime}$ of LiF $B$ shows an opposite behaviour : at low cooling rates it reaches its maximal height and decreases at higher cooling rates. 
The dependence of the temperature position of the LiF B TL main peak on the thermal history of the crystal can also be demonstrated by certain preirradiation thermal treatments e. $\mathrm{g}$. as performed on TLD 100 by Zimmerman et al. [1]. Figure 6, solid lines, shows a normal glow curve of $\mathrm{LiF} B$ after standard annealing for $1 \mathrm{~h}$ at $480^{\circ} \mathrm{C}$ with a subsequent cooling rate of $10 \mathrm{~K} \mathrm{min.}^{-1}$ in comparison with a glow curve obtained after a first $\left(1 \mathrm{~h}, 480{ }^{\circ} \mathrm{C}, 10 \mathrm{~K} \mathrm{~min} .^{-1}\right)$ plus a second thermal treatment $\left(3 \mathrm{~h}, 190^{\circ} \mathrm{C}, 200 \mathrm{~K} \mathrm{~min}^{-1}\right)$. The standard annealing treatment leads to a glow curve with low pre-peaks and a high TL peak 5 (not $5^{\prime}$ ), the two step treatment drastically increases the pre-peaks very similar to TLD $100 / 1 /$ and destroys TL peak 5 nearly completely. A three step treatment $\left(1 \mathrm{~h}, 480^{\circ} \mathrm{C}, 10 \mathrm{~K} \mathrm{min.}{ }^{-1} ; 3 \mathrm{~h}, 190^{\circ} \mathrm{C}, 200 \mathrm{~K} \mathrm{~min}^{-1}\right.$; $1 \mathrm{~h}, 210^{\circ} \mathrm{C} . .240^{\circ} \mathrm{C}, 200 \mathrm{~K} \mathrm{~min}^{-1}$ ) leads to glow curves as shown in figure 6 , dashed lines. The prepeaks decrease with increasing third step temperature and simultaneously TL peak $5^{\prime}$ is produced, increasing with third step temperature and shifting slightly towards the temperature position of peak 5 due to a growing peak 5 component overlapping peak $5^{\prime}$.

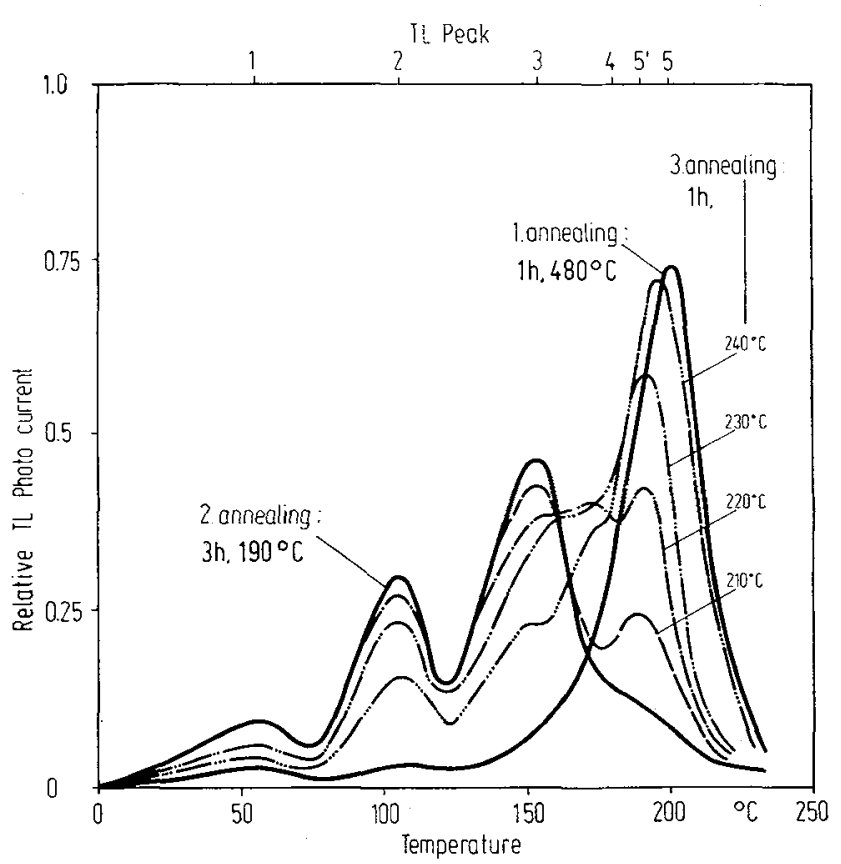

FIG. 6. - Glow curves of LiF B after various pre-irradiation thermal treatments. 1 . annealing: $480^{\circ} \mathrm{C}, 1 \mathrm{~h}$, cooling rate $10 \mathrm{~K}$ min. ${ }^{-1} ; 2$. annealing: 1 . annealing plus $190^{\circ} \mathrm{C}, 3 \mathrm{~h}$, cooling rate $200 \mathrm{~K} \mathrm{min.}{ }^{-1}$; 3. annealing : 2 . annealing plus $210^{\circ} \mathrm{C}$... $240^{\circ} \mathrm{C}, 1 \mathrm{~h}$, cooling rate $200 \mathrm{~K} \mathrm{min.}^{-1}$

4. Discussion. - As can be seen from the measurements LiF A behaves very similarly to Harshaw TLD 100 concerning TL response, glow curve shape, ratio of TL peak 5 to TL peak 2, the dependence of the heights of these peaks on the cooling rate after high temperature annealing and the appearance of the $200 \mathrm{~nm}(6.2 \mathrm{eV}) \mathrm{Ti}$ optical absorption band. A comparison of the height of TL peak 5 of LiF A (Fig. 5) and the height of the optical absorption band at $310 \mathrm{~nm}$ $(4.0 \mathrm{eV})$ (Fig. 3) of the same material - both functions of the cooling rate-coarsely demonstrates proportionality, thus confirming the wellknown relationship between defects responsible for the $310 \mathrm{~nm}$ absorption band and TL peak 5 respectively $[10,11]$. Therefore, LiF A is a conventional LiF TLD material as often has been investigated and described in the literature.

However, LiF B appears to differ in several respects :

1) Favourably - in regard of TLD application the main TL peak $5+5^{\prime}$ reveals TL response equal to conventional material but the pre-peaks are much lower. Further, the dependence of the height of TL peak $5+5^{\prime}$ on the cooling rate behaves contrary to conventional material, low cooling rates are necessary to obtain optimal TL response, an advantage for application too because quenching as favourable for conventional material easily leads to mechanical defects of solid detectors.

2) The $200 \mathrm{~nm}$ Ti optical absorption does not appear in $\mathrm{LiF}$ B. As Ti is necessary to obtain TL emission [15] and as the spectral distribution of the TL emission had been found to be equal to the emission of conventional material (a broad emission band peaking around $400 \mathrm{~nm}$ ) we conclude that doping with $\mathrm{T} i$ leads to a certain defect configuration acting as the TL activator, but this activator does not create the $200 \mathrm{~nm}$ Ti absorption band which otherwise should be seen in the absorption spectrum of LiF B. Therefore, as the total Ti concentration of our LiF $A$ and $\mathrm{LiF} \mathrm{B}$ are similar, probably a large portion of $\mathrm{Ti}$ in $\mathrm{LiF} B$ does not form activators, but certain different defects similar to $\mathrm{LiF} \mathrm{A}$, in which a large portion of Ti forms $200 \mathrm{~nm}$ absorption centres. The only difference of $\mathrm{LiF} \mathrm{A}$ and $\mathrm{LiF} B$ is the Ti pre-doping of the latter and we actually cannot explain the marked difference in the resulting materials.

3) The dependences of TL peak $5+5^{\prime}$ and the $310 \mathrm{~nm}$ optical absorption band of $\mathrm{LiF} \mathrm{B}$ on the cooling rate run in opposite directions. While the $310 \mathrm{~nm}$ absorption band decreases with decreasing cooling rate like in conventional material, glow peak $5+5^{r}$ increases. Considering peak $5+5^{\prime}$ to be a composed glow peak this can easily be explained by the assumption that only defects creating the TL peak 5 component lead to $310 \mathrm{~nm}$ optical absorption whereas TL peak $5^{\prime}$ defects do not.

Taking the $310 \mathrm{~nm}$ absorption band height of LiF B (Fig. 4) as a measure for the concentration of TL peak 5 traps one qualitatively may estimate an increase of the TL peak 5 component in $\mathrm{LiF}$ B with raising cooling rate between $0.17 \mathrm{~K} \mathrm{~min} .^{-1}$ and $60 \mathrm{~K} \mathrm{min.} .^{-1}$ similar to $\mathrm{LiF}$ A but with lower glow peak height. From the thermal position of TL peak $5+5^{\prime}$ (Fig. 2) after cooling with $60 \mathrm{~K} \mathrm{min.} .^{-1}$ can be concluded that at higher cooling rates peak $5+5^{\prime}$ is highly governed 
by the peak 5 component which decreases with increasing cooling rate (see Fig. 5). Thus, the peak 5 component of peak $5+5^{\prime}$ runs through a maximum around $60 \mathrm{~K} \mathrm{min.}{ }^{-1}$ (somewhat similar to what Bradbury et al. [4] found for TL peak 4 of TLD 100).

At low cooling rates TL peak $5+5^{\prime}$ of $\mathrm{LiF} \mathrm{B}$ is governed by the peak $5^{\prime}$ component. It is striking that this component also can be observed at conventional LiF (TLD 100, LiF A). Bradbury et al. [4], figure 2 show a strong decrease and a shift of TL peak 5 of TLD 100 towards lower temperature within about $10^{\circ} \mathrm{C}$ after a cooling rate of $0.06 \mathrm{~K} \mathrm{~min} .^{-1}$. LiF A exhibits the same effect after a cooling rate of $0.17 \mathrm{~K}$ min. ${ }^{-1}$ (see Fig. 1). Thus, in principle, glow peak $5^{\prime}$ is producable in every LiF TLD material, but, its appearance is very pronounced in our $\mathrm{LiF} B$.

Nothing is known in detail about the structure of the defects which create TL peak $5^{\prime}$, only some properties may be summarized:

1) They need a certain special kind of incorporating $\mathrm{Ti}$ to $\mathrm{LiF}$ for their formation.
2) They do not give rise for a marked optical absorption at least in the spectral region between $180 \mathrm{~nm}$ and $440 \mathrm{~nm}$.

3) The TL peak $5^{\prime}$ defects are probably also connected to $\mathrm{Mg}$ impurities because their build-up (see Fig. 6) is coupled with a decay of the pre-peaks which without any doubt are due to $\mathrm{Mg}$ impurities.

4) Their production needs temperatures above $200^{\circ} \mathrm{C}$ but below the temperature necessary for the creation of TL peak 5 defects (Fig. 6).

5) In contrast to TL peak 5 defects which are destroyed TL peak $5^{\prime}$ defects are favoured at low cooling rates.

A definite statement about the trapping defects leading to TL peak 5' can be expected, if the nature of the traps responsible for the common TL peaks 1 to 5 are really clearified. 60 LiF B crystals have already been applied successfully as TLD detectors [18]. Low TL pre-peaks and simple thermal treatment necessary for re-use practically turned out to be an improvement.

\section{References}

[1] Zimmerman, D. W., Rhyner, C. R. and Cameron, J. R., Health Phys. 12 (1966) 525.

[2] Carlsson, C. A., Phys. Med. Biol. 14 (1969) 107.

[3] Dhar, A., Dewerd, L. A. and Stoebe, T. G., Health Phys. 25 (1973) 427.

[4] Bradbury, M. H., Nwosu, B. C. E. and Lilley, E., J. Phys. D : Appl. Phys. 9 (1976) 1009.

[5] BECKer, K., Solid State Dosimetry (CRC Press, Cleveland, Ohio) 1973.

[6] Stoebe, T. G. and Watanabe, S., Phys. Status Solidi (a) 29 (1975) 11.

[7] Grant, R. M. and Cameron, J. R., J. Appl. Phys. 37 (1966) 3791.

[8] Dryden, J. S. and Shuter, B., J. Phys. D : Appl. Phys. 6 (1973) 123.

[9] Mayhugh, M. R., Christy, R. W. and Johnson, N. M., Proc. II. Intern. Conf. Luminescence Dosimetry, U. S. A. E. C. Conf. $680920(1968) 294$.
[10] JaCkson, J. H. and Harris, A. M., J. Phys. C : Solid State Phys. 3 (1970) 1967.

[11] Nink, R. and Kos, H.-J., Phys. Status Solidi (a) 35 (1976) 121.

[12] Zimmerman, D. W. and Jones, D. E., Appl. Phys. Lett. $10(1967) 82$.

[13] Rossiter, M. J., Rees-Evans, D. B. and Ellis, S. C., Proc. III. Intern. Conf. Luminescence Dosimetry, Risø, Danish Atomic Energy Commission, Roskilde, Denmark (1971) 1002.

[14] Rossiter, M. J., Rees-Evans, D. B., Ellis, S. C. and Griffiths, J. M., J. Phys. D : Appl. Phys. 4 (1971) 1245.

[15] Nink, R., PTB-Mitt. 85 (1975) 441.

[16] Johnson, T. L., Proc. IV Intern. Conf. Luminescence Dosimetry, Krakow, Inst. of Nucl. Physics, 1974, p. 197.

[17] Townsend, P. D. and Kelly, J. C., Color Centres and Imperfections in Isolators and Semiconductors (Sussex Univ. Press) 1973.

[18] NINK, R., PTB-Mitt, to be published.

\section{DISCUSSION}

M. C. WinTersGill. - 1) What was the purpose of the addition of silica to the $\mathrm{LiF}$ ?

2) Does this not increase the probability of introducing impurities which may poison the trapping or luminescence centres thus producing the differences in glow curves between the two types of $\mathrm{LiF}$ used.

3) Might it be possible to identify such an impurity which appears to suppress the lower temperature glow peaks.
R. NINK. - 1) To increase the overall TL-response of $\mathrm{LiF} \mathrm{A}$ as well as $\mathrm{LiF} \mathrm{B}$.

2) As the concentration of $\mathrm{Si}$ and the way of doping are similar in both crystal types we do not believe in a special action of $\mathrm{Si}$ in one of our crystal types. We believe that $\mathrm{Si}$ more probably aids the formation or action of the activators.

3) We hope so, but we have not yet got any significant results concerning this question. 